\title{
Comparison of intraoperative ultrasonography guidance with an open surgical method for venous port catheter placement in chemotherapy
}

\author{
(1) Ozan Onur Balkanay, ${ }^{1,2}$ (1) Suleyman Demiryas ${ }^{3}$ \\ ${ }^{1}$ Department of Cardiovascular Surgery, Manisa Government Hospital, Manisa, Turkey \\ 2Department of Cardiovascular Surgery, Cerrahpasa Medical Faculty, Istanbul University-Cerrahpasa, Istanbul, Turkey \\ ${ }^{3}$ Department of General Surgery, Cerrahpasa Medical Faculty, Istanbul University-Cerrahpasa, Istanbul, Turkey
}

\begin{abstract}
OBJECTIVE: One of the leading venous access methods in chemotherapy is the use of a venous port catheter (VPC). An open surgical or ultrasound-guided technique can be performed. In our study, the VPC placement via both of these techniques was compared.
\end{abstract}

METHODS: A total of 180 consecutive patients who underwent the VPC placement procedure either via the open or ultrasound-guided methods in two centers between January 2014 and January 2016 were included in the study. Patients' data were reviewed retrospectively. Groups were compared in terms of intervention-related complication rates, a total procedure time, and the requirement of control imaging with ionizing radiation.

RESULTS: The mean total procedure time was significantly shorter $(19.5 \pm 4.6 \mathrm{~min}, 46.7 \pm 19.6 \mathrm{~min}, \mathrm{p}<0.001)$ in the ultrasound-guided group than the open method. The rate of catheter malposition was significantly less in the ultrasound-guided group than in the open group $(p<0.001)$. The need for per-operative imaging with ionizing radiation and the need of reversion in the preferred technique were not observed in the ultrasound-guided group, whereas in the open group, they were observed in $90(100 \%)$ and $6(6.7 \%)$ patients, respectively $(p<0.001, p=0.01)$.

CONCLUSION: Intraoperative ultrasound guidance for the VPC placement shortens the processing time and eliminates the need for routine imaging methods that require the use of ionizing radiation. In accordance with the current guidelines recommendations, intraoperative ultrasonography should be preferred as much as possible during the VPC placement. However, the need for the surgical teams in centers to maintain the necessary educational processes for both techniques should not be overlooked.

Keywords: Central; interventional, ultrasound; operative procedures; venous catheterization.

Cite this article as: Balkanay OO, Demiryas S. Comparison of intraoperative ultrasonography guidance with an open surgical method for venous port catheter placement in chemotherapy. North Clin Istanb 2019;6(3):279-283.

Tn patients with malignancy, there is an increasing need for 1 a better venous access for blood sampling in the routine control, parenteral fluid and blood products administration, and chemotherapy applications [1]. One of the leading methods in the venous access for chemotherapy is the placement of a venous port catheter (VPC) [2]. VPC systems, which are used for these purposes, allow multiple punctures [1]. Open surgical or ultrasound-guided techniques can be both performed in this procedure [1-3]. In our study, patients who were planned to undergo chemotherapy and underwent the VPC placement either via the open surgical or the ultrasound-guided technique were compared. 


\section{MATERIALS AND METHODS}

A total of 180 consecutive patients who underwent the VPC placement for chemotherapy either via an open surgical method or with an ultrasound-guided technique in two centers between January 2014 and January 2016 were included in the study after the informed consent was obtained. Study was approved by the local ethics committee (approval number: 83045809-604.01.02A-25). Both techniques were used in both centers. Patients' data were reviewed, and the study was conducted retrospectively in accordance with the principles of the Helsinki Declaration. Statistical comparisons were made between the two groups in terms of demographic variables, intervention-related complication rates, a total procedure time, and the requirement of control imaging with ionizing radiation. A routine pre-interventional ultrasound evaluation was performed for the puncture/ surgical intervention sites. All patients were monitored via ECG tracing, pulse oximetry, and blood pressure measurements during the procedure.

During the ultrasound-guided technique, an ultrasound probe was covered with a sterile sheath and positioned in the surgical field. Both the ipsilateral and contralateral sites of the subclavian and internal jugular vein regions were prepared and draped for the ultrasound evaluation for malposition. In addition, if the advancement of the guide wire failed, other sites were ready in the surgical field. During the procedure, 1\% lidocaine hydrochloride was used for local anesthesia. All ultrasound-guided punctures were made in the right internal jugular vein site. The guide wire image in the venous lumen was evaluated at the puncture site as well as other contralateral and ipsilateral venous regions. In the ultrasound-guided technique, the length of the catheter line was measured externally and individually in a patientbased manner. Then, the catheter line was propagated to the puncture sheath via the right internal jugular vein.

The skin incision in the delto-pectoral sulcus region was made, and a pocket for the main body of VPC was prepared in both techniques. In the ultrasound-guided technique, the proximal part of the catheter line was passed through a curved $\mathrm{C}$-shaped tunnel to reach the delto-pectoral pocket region. The open surgical technique included the exploration of the cephalic vein and the placement of the catheter line via cephalic vein.

Routine X-ray imaging control was used in the open surgical technique for the validation of the catheter posi- tion. In addition, the length of the catheter line was determined using this control imaging in the open surgical technique as well. The connection between the line and the main body was then made, and the main body of the VPC was placed into the delto-pectoral pocket in both techniques. Stay sutures were used to fix the VPC main body. The VPC was controlled via blood aspiration, and then main body and catheter line were washed out with $10 \mathrm{~mL}$ of saline solution, which included $50 \mathrm{IU} / \mathrm{mL}$ standardized heparin.

\section{Statistical Analysis}

Categorical variables were expressed as the number (percentage) and continuous variables as the mean \pm standard deviation. Categorical variables were compared using the chi-squared test and Fisher's exact test, and continuous variables using Student's t-test. The p-value of $<0.05$ was considered statistically significant. The IBM SPSS software package version 21.0 (SPSS, Chicago, IL, USA) was used for statistical analysis.

\section{RESULTS}

There were 90 patients in both groups. The mean age of all patients was $58.7 \pm 11.9$ years. Sixty-nine patients $(38.3 \%)$ were female. There were no significant differences between the two groups in terms of demographic data such as age and gender (Table 1). The mean duration of the intervention for all patients was $33.1 \pm 19.7$ minutes. The mean total procedure time was significantly shorter $(19.5 \pm 4.6 \mathrm{~min}, 46.7 \pm 19.6 \mathrm{~min})(\mathrm{p}<0.001)$ in the procedures performed with the ultrasound-guided technique than the open surgical technique (Table 2). The rate of catheter malposition was significantly less in the ultrasound-guided technique group than in the open surgical technique group (0 [0\%], 34 [37.8\%], respectively) $(\mathrm{p}<0.001)$. All catheter malpositions were corrected under the guidance of fluoroscopy in the open

TABLE 1. Demographic variables

\begin{tabular}{lccc} 
Variable & OST $(\mathrm{n}=90)$ & UGT $(\mathrm{n}=90)$ & $\mathrm{p}$ \\
\hline Age (years) mean \pm SD & $57.6 \pm 12.4$ & $59.8 \pm 11.3$ & 0.22 \\
Gender (female) $\mathrm{n}(\%)$ & $35(38.9)$ & $34(37.8)$ & 0.88 \\
\hline
\end{tabular}

OST: Open surgical technique; UGT: Ultrasound guided technique; SD: Standard deviation. 
TABLE 2. Intervention-related variables

Variable

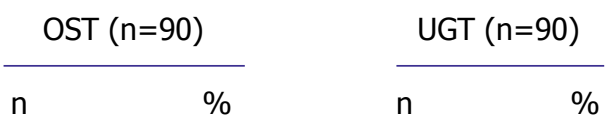

Total number of vein punctures (mean \pm SD)

Duration of the intervention/surgery (minutes) (mean \pm SD)

Need of reversion in the preferred technique*

Control imaging including ionizing radiation

Complications (total)

Arterial puncture

External bleeding

Local hematoma

Pneumothorax

Catheter malpositioning

Early catheter dysfunction

$-$

\begin{tabular}{cc}
\multicolumn{2}{c}{-} \\
\multicolumn{2}{c}{$46.7 \pm 19.6$} \\
6 & 6.7 \\
90 & 100 \\
39 & 43.3 \\
0 & 0 \\
2 & 2.2 \\
2 & 2.2 \\
1 & 1.1 \\
34 & 37.8 \\
0 & 0
\end{tabular}

\section{$1.1 \pm 0.3$}

$19.5 \pm 4.6$

$0 \quad 0$

$0 \quad 0$

1.1

0

0

1.1

0

0

0 $p$

*: Reversion to open surgical technique in the failure of the ultrasound guided technique or reversion to the ultrasound guided technique in the failure of the open surgical technique. OST: Open surgical technique; UGT: Ultrasound guided technique; SD: Standard deviation.

surgical technique. The total rate of complications except the catheter malposition for all patients was 6 of $180(3.3 \%)$. The rates of arterial puncture, bleeding, local hematomas, pneumothorax, and early catheter dysfunction were similar for both groups $(p>0.05)$. Pneumothorax developed in one patient $(1.1 \%)$ in the open surgical technique group. This patient had the need of reversion in the preferred technique and had multiple punctures by using an anatomical landmark technique in the right subclavian vein region. The need for per-operative imaging with ionizing radiation and the need of reversion in the preferred technique were not observed in the ultrasound-guided technique group, whereas in the open surgical technique group, they were observed in 90 patients (100\%), and six patients $(6.7 \%)$, respectively $(\mathrm{p}<0.001 ; \mathrm{p}$ $=0.01)$. Among these six patients in whom the preferred techniques were reversed, four of them were catheterized in the right subclavian vein region and two of them in the right internal jugular vein region.

\section{DISCUSSION}

The total number of venous puncture requirements is increased for various reasons in patients with malignancy [1]. Therefore, the VPC placement can be a life-saving procedure for these patients. VPCs have a special membrane at their puncture site allowing multiple punctures [1]. There are two major techniques for the VPC place- ment that have been previously described: an open surgical exploration technique and ultrasound-guided technique. It is a conventional method of placement of the VPC, which is considered to be the insertion of the port catheter line by exploration of the cephalic vein with the open surgical technique. The placement of the VPC by surgical exploration of the vein is considered to have a lower risk of damage to the adjacent arterial and neural structures than those using blind anatomical landmark puncture techniques. However, due to higher procedural success rates, the VPC placement with the subclavian or internal jugular vein puncture has begun $[4,5]$. The risk of pneumothorax, hemothorax, arterial puncture, hematoma development, or catheter malposition is present during both VPC implantation techniques [6$8]$. To place the catheter in the proper position, imaging methods are frequently used for verification purposes. The most commonly used imaging methods are direct radiographic or fluoroscopic imaging with ionizing radiation. There are also additional methods including the ultrasound-guided technique used in the detection of complications such as the malposition of the catheter and pneumothorax [9]. It is currently not recommended to routinely use $\mathrm{X}$-ray imaging methods for position confirmation during and after the VPC placement [10-13]. However, the use of $\mathrm{X}$-ray imaging is recommended if a clinical suspicion suggests pneumothorax presence [1]. At this point, performing an open surgical procedure re- 
quires an imaging confirmation, even though it provides an advantage for catheter positioning. In addition, in the open surgical procedure, the position of the catheter line was determined during the confirmation with the use of the ionizing radiation imaging method, while the catheter length was determined individually by the patient-based external line measurement in ultrasound-guided procedures. In our study, all of 90 patients in the open surgical technique group needed per-operative imaging with ionizing radiation, while none of the patients needed it in the ultrasound-guided technique group $(p<0.001)$. The main explanation of this major difference was about the procedure requirement. The approach in the surgical group included the advancement of the guide wire through the subclavian vein. This region had a high risk of malposition to the contralateral subclavian, as well as the ipsilateral internal jugular vein. Therefore, in the open surgical technique group, the position of the guide wire and the catheter usually had to be validated using intraoperative imaging with ionizing radiation.

Furthermore, open surgical procedures can prolong the processing time. We found that the mean total procedure time was significantly shorter in the ultrasound-guided technique group $(19.5 \pm 4.6 \mathrm{~min})$ than in the open surgical technique group $(46.7 \pm 19.6 \mathrm{~min})$ $(\mathrm{p}<0.001)$. For this reason, the ultrasound-guided technique can be used more frequently nowadays with the distinct advantages for the placement of VPC for chemotherapy [14-19].

In addition, it was found to be safe and effective to place the line of the VPC systems in the right internal jugular vein with the ultrasound-guided technique [1]. Due to the continuity of the right internal jugular vein with the superior vena cava and right atrium, the possibility of catheter malposition is significantly reduced. Although there have been some studies describing the single-incision techniques for the VPC placement, complications including the arterial puncture, vein thrombosis, and a malpositioned guide wire were also described [20]. Contrary to these findings, we found no such complications in the ultrasound-guided technique via the right internal jugular vein. As in the case of the VPC placement, the use of ultrasonography in the central venous catheterization provides significant advantages both before and during the procedure [21].

The use of the ultrasound-guided technique may allow a faster confirmation of the catheter position [21, $22]$. Catheter malposition has been reported in the cen- tral venous catheterizations in $2 \%-37 \%$ of cases $[6,23$, 24]. Herein, the anatomic position, extension of the vein, and the presence of collateral veins in which the puncture is to be performed is important. In addition, distal vein site punctures carry a greater malposition risk than those performed from a more proximal vein. In terms of the anatomic position advantage, the use of the right internal jugular vein region instead of the subclavian vein comes out to the forefront $[6,25]$. For these reasons, the right internal jugular vein region was preferred in all our ultrasound-guided procedures. In our study, we found that the rate of the catheter malposition was significantly less in the ultrasound-guided technique group than in the open surgical technique group $(0[0 \%], 34$ [37.8\%], respectively) ( $\mathrm{p}<0.001)$.

The development of pneumothorax is reported in $0.5 \%-3 \%$ of central venous catheterization procedures $[10,26]$. The risk of developing pneumothorax has also been reported in punctures performed in the right internal jugular vein $[14,19]$. More ratios than these series have been reported in the series where the subclavian vein puncture was preferred [25]. In our study, pneumothorax was developed in one patient $(1.1 \%)$ in the open surgical technique group. This patient needed reversion in the preferred technique and had multiple punctures in the right subclavian vein region. At this point, the use of the blunt anatomical landmark technique, subclavian vein as puncture zone, and the need for multiple punctures are leading factors that increase the risk of pneumothorax development $[1,25,26]$. To reduce this risk, it was suggested that the ultrasoundguided technique should be preferred before and during the procedure and that the right internal jugular vein site should be preferred as the puncture region [1]. In parallel to these literature suggestions, in our study, it was shown that preferring the right internal jugular vein as the puncture region and performing the procedure with the ultrasound-guided technique could help to minimize possible risks. If the center has the facility, it is recommended to prefer ultrasound-guided procedures. It should be however kept in mind that explicit instructions must also be applied to complete the learning curve, which is necessary for open surgical intervention in emergencies, at all centers.

On the other hand, the retrospective conduction and a small number of patients could be accepted as limitations to our study. However, the results of comparison of two different techniques could inspire further studies. 


\section{Conclusion}

The intraoperative ultrasound-guided technique for venous port catheter placement shortens the procedure time and eliminates the need for routine imaging methods that require the use of ionizing radiation. In accordance with the recommendations of the current guidelines, intraoperative ultrasonography should be preferred as much as possible during the VPC placement [27]. However, the need for the surgical teams in centers to maintain the necessary educational processes for both techniques should not be overlooked.

Ethics Committee Approval: Istanbul University-Cerrahpasa, Cerrahpasa faculty of Medicine, the local ethics committee date/approval number: 2018/ 83045809-604.01.02-A-25.

Conflict of Interest: No conflict of interest was declared by the authors.

Financial Disclosure: The authors have no proprietary or financial interest in any products used in this study.

Authorship Contributions: Concept - OOB, SD; Design - OOB, SD; Supervision - OOB, SD; Materials - OOB, SD; Data collection and/or processing - OOB, SD; Analysis and/or interpretation - OOB, SD; Writing - OOB, SD; Critical review - OOB, SD.

\section{REFERENCES}

1. Miccini M, Cassini D, Gregori M, Gazzanelli S, Cassibba S, Biacchi D. Ultrasound-Guided Placement of Central Venous Port Systems via the Right InternalJugular Vein: Are Chest X-Ray and/or Fluoroscopy Needed to Confirm the CorrectPlacement of the Device? World J Surg 2016;40:2353-8. [CrossRef]

2. Niederhuber JE, Ensminger W, Gyves JW, Liepman M, Doan K, Cozzi E. Totally implanted venous and arterial access system to replace external catheters in cancer treatment. Surgery 1982;92:706-12.

3. de Gregorio MA, Miguelena JM, Fernández JA, de Gregorio C, Tres A, Alfonso ER. Subcutaneous ports in the radiology suite: an effective and safe procedure for care in cancer patients. Eur Radiol 1996;6:748-52.

4. Seiler CM, Frohlich BE, Dorsam UJ, Kienle P, Buchler MW, Knaebel HP. Surgical technique for totally implantable access ports (TIAP) needs improvement: a multivariate analysis of 400 patients. J Surg Oncol 2006;93:24-9. [CrossRef]

5. McGee WT, Ackerman BL, Rouben LR, Prasad VM, Bandi V, Mallory DL. Accurate placement of central venous catheters: a prospective, randomized, multicenter trial. Crit Care Med 1993;21:1118-23. [CrossRef]

6. Yilmazlar A, Bilgin H, Korfali G, Eren A, Ozkan U. Complications of 1303 central venous cannulations. J R Soc Med 1997;90:319-21. [CrossRef]

7. Patel RY, Friedman A, Shams JN, Silberzweig JE. Central venous catheter tip malposition. J Med Imaging Radiat Oncol 2010;54:35-42.

8. Plumhans C, Mahnken AH, Ocklenburg C, Keil S, Behrendt FF, Günther RW, et al. Jugular versus subclavian totally implantable access ports: catheter position, complications and intrainterventional pain perception. Eur J Radiol 2011;79:338-42. [CrossRef]

9. Lichtenstein D, Mezière G, Biderman P, Gepner A. The comet-tail artifact: an ultrasound sign ruling out pneumothorax. Intensive Care Med 1999;25:383-8. [CrossRef]

10. Brown JR, Slomski C, Saxe AW. Is routine postoperative chest $\mathrm{x}$-ray necessary after fluoroscopic-guided subclavian central venous port placement? J Am Coll Surg 2009;208:517-9. [CrossRef]

11. Losert H, Prokesch R, Grabenwöger M, Waltl B, Apsner R, SunderPlassmann $G$, et al. Inadvertent transpericardial insertion of a central venous line with cardiac tamponade failure of preventive practices. Intensive Care Med 2000;26:1147-50. [CrossRef]

12. Vezzani A, Brusasco C, Palermo S, Launo C, Mergoni M, Corradi F. Ultrasound localization of central vein catheter and detection of postprocedural pneumothorax: an alternative to chest radiography. Crit Care Med 2010;38:533-8. [CrossRef]

13. van Beek EJ. Routine chest radiographs following central line insertion: not always necessary! Chest 2005;127:10-2. [CrossRef]

14. Ahn SJ, Kim HC, Chung JW, An SB, Yin YH, Jae HJ, et al. Ultrasound and fluoroscopy-guided placement of central venous ports via internal jugular vein: retrospective analysis of 1254 port implantations at a single center. Korean J Radiol 2012;13:314-23. [CrossRef]

15. Sanabria A, Henao C, Bonilla R, Castrillón C, Cruz H, Ramírez W, et al. Routine chest roentgenogram after central venous catheter insertion is not always necessary. Am J Surg 2003;186:35-9. [CrossRef]

16. Gebauer B, El-Sheik M, Vogt M, Wagner HJ. Combined ultrasound and fluoroscopy guided port catheter implantation--high success and low complication rate. Eur J Radiol 2009;69:517-22. [CrossRef]

17. Maury E, Guglielminotti J, Alzieu M, Guidet B, Offenstadt G. Ultrasonic examination: an alternative to chest radiography after central venous catheter insertion? Am J Respir Crit Care Med 2001;164:403-5.

18. Dede D, Akmangit I, Yildirim ZN, Sanverdi E, Sayin B. Ultrasonography and fluoroscopy-guided insertion of chest ports. Eur J Surg Oncol 2008;34:1340-3. [CrossRef]

19. Cavanna L, Civardi G, Vallisa D, Di Nunzio C, Cappucciati L, Bertè $\mathrm{R}$, et al. Ultrasound-guided central venous catheterization in cancer patients improves the success rate of cannulation and reduces mechanical complications: a prospective observational study of 1,978 consecutive catheterizations. World J Surg Oncol 2010;8:91. [CrossRef]

20. Seo TS, Song MG, Kang EY, Lee CH, Yong HS, Doo K. A single-incision technique for placement of implantable venous access ports via the axillary vein. J Vasc Interv Radiol 2014;25:1439-46. [CrossRef]

21. Balkanay OO. The use of Doppler ultrasound and double-control method during catheterization for hemodialysis. Damar Cer Derg 2017;26:104-10.

22. Gekle R, Dubensky L, Haddad S, Bramante R, Cirilli A, Catlin T, et al. Saline Flush Test: Can Bedside Sonography Replace Conventional Radiography for Confirmation of Above-the-Diaphragm Central Venous Catheter Placement? J Ultrasound Med 2015;34:1295-9. [CrossRef]

23. Trerotola SO, Thompson S, Chittams J, Vierregger KS. Analysis of tip malposition and correction in peripherally inserted central catheters placed at bedside by a dedicated nursing team. J Vasc Interv Radiol 2007;18:513-8. [CrossRef]

24. Venkatesan T, Sen N, Korula PJ, Surendrababu NR, Raj JP, John P, et al. Blind placements of peripherally inserted antecubital central catheters: initial cathetertip position in relation to carina. Br J Anaesth 2007;98:83-8. [CrossRef]

25. Miao J, Ji L, Lu J, Chen J. Randomized clinical trial comparing ultrasound-guided procedure with the Seldinger's technique for placement of implantable venous ports. Cell Biochem Biophys 2014;70:559-63.

26. Mudan S, Giakoustidis A, Morrison D, Iosifidou S, Raobaikady R, Neofytou K, et al. 1000 Port-A-Cath ${ }^{\oplus}$ placements by subclavian vein approach: single surgeon experience. World J Surg 2015;39:328-34.

27. Frykholm P, Pikwer A, Hammarskjöld F, Larsson AT, Lindgren S, Lindwall R, et al. Clinical guidelines on central venous catheterisation. Swedish Society of Anaesthesiology and Intensive Care Medicine. Acta Anaesthesiol Scand 2014;58:508-24. [CrossRef] 